\title{
Post aus der Brachzone
}

Erhard Taverna

erhard.taverna[at]saez.ch
Schwierig, dieses Schleifen, wenn die Hände zittern und jeder Windstoss tanzende Schatten erzeugt. Mit dem Daumen prüft er im hellen Umkreis der Petrollampe die abgeschrägten Stahlspitzen. Sind sie wieder scharf, schiebt er einen Draht durch die Kanülen und taucht die Nadeln mit den zerlegten Spritzen in das kochende Wasser. Bald sind auch die Ampullen aufgebraucht, dann kann er sich das Zusammenschrauben der Stempel und Glaszylinder sparen. In welchem Jahr kam der Lieferwagen zum letzten Mal? War damals die Poststelle schon aufgehoben? Die Strasse im Tobel ging danach wörtlich bachab, und im Winter haben nicht einmal Fussgänger eine Chance durchzukommen. Das ist das einzige Gute daran, denkt er beim Aufrollen der gesäuberten Binden, die Leute gehen wieder $\mathrm{zu}$ Fuss. Die wenigen, die geblieben sind, einige Alte in ihren Ruinen und

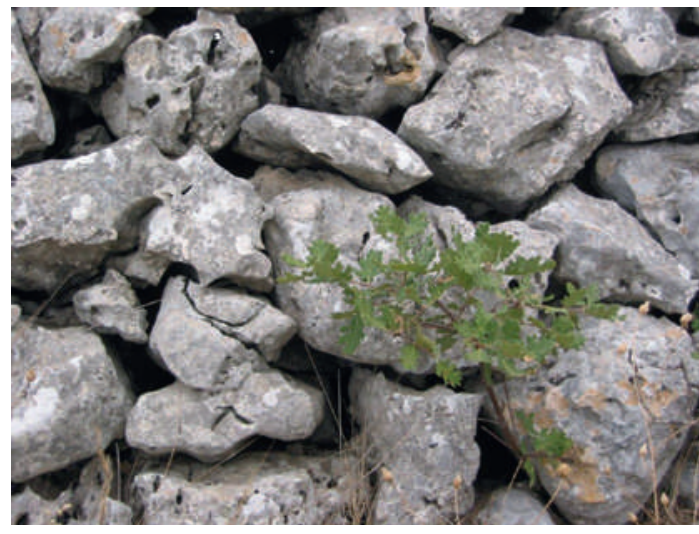

regnet, steht sie leer. Was geschieht hier?, hatte er sich verwundert gefragt und dabei, trotz Anspruch auf Entschädigung, seinen eigenen Wegzug verpasst. Nicht aus Pflichtgefühl, nein, nichts Heroisches. Was ihn hielt, war die Abwesenheit familiärer Verpflichtungen. Auch Trägheit, Angst vor einem Neubeginn und, zugegeben, eine morbide Neugier auf das, was der einsetzende Verfall noch bringen mochte. Zeuge dieser geplanten Verwilderung wollte er sein, ein Überlebender, dessen Berichte in Fachblättern gelesen und über alle Medien verbreitet würden. Vielleicht mit Schlagzeilen wie «Der Hausarzt, der aus der Kälte kam» oder so ähnlich. Wunschgedanken, letzte Anfälle von Grössenwahn, die spurlos zerstoben in den verlassenen Räumen des verlotterten Hauses und in zunehmend verwirrten Gedankengängen. Auch in den Zwischenzodie Familien auf den abgelegenen Höfen. «Medizin im Rückbau» hatte er einmal notiert und seinen Verdruss seitenlang weggeschrieben. Bald sind alle Pharmakalender vollgekritzelt und seine Chronik abgeschlossen. Das Lesen mit der Lupe macht zunehmend Mühe.

Die Uhr am Handgelenk zieht er nicht mehr auf. Ein Andenken, schliesslich war man früher etwas Besseres. Doch mehr als Tages- und Jahreszeiten braucht der Mensch hier nicht. Anfangs empörten sich die Leute, weil mit der Tankstelle auch der Bancomat verschwand. Nach dem Bauboom wanderten die letzten Handwerker ab. Ein Laden nach dem anderen wurde geschlossen, da hatte es auch das Geld nicht mehr gebraucht. Er legt Holz nach und hört im Kamin den Wind heulen. Unter dem Dach lärmen die Marder, und aus den knarrenden Wänden rieselt feiner Holzstaub in die trübe Dämmerung.

Kurz nachdem der Mobilfunk ausfiel, kam es zu den ersten längeren Stromausfällen. Das waren keine Pannen. Wer Doppelfenster hat, lagert sein Gemüse zwischen den Scheiben und holt die alten Einmachgläser aus dem Keller. Die paar verbliebenen Kinder, denen er auf die Welt half, werden zu Hause unterrichtet, wenn überhaupt. Das Holz der Schulbänke ist längst verfeuert. In der Turnhalle wurde Heu gelagert, aber seit es durch die kaputten Fenster hinein- nen steht die Zeit nicht still. Sie ändert unbemerkt ihre Richtung und läuft nun rückwärts. Der Wald schiebt sich heran und schickt seine Vorboten ins Dorf. Eschen und Hasel wachsen aus eingesunkenen Dächern und Strassenspalten. Der Schwarzdorn zwängt auf dem Dorfplatz die Pflästerung auseinander, und in den Vorgärten lösen Tannen die Birken ab. Die wenigen Patienten bringen Eier und Speck, auch mal ein Huhn oder Brot. Für Zucker und Honig gibt es am meisten Tarifpunkte, und für einen richtigen Kaffee würde er fast alles tun. Kartoffeln und Zwiebeln wachsen auf dem Balkon. Einige Leute gehen ungehindert das ganze Jahr über auf die Jagd. Ohne Behörden und Kirche verändern sich die Verbliebenen zu Stammesangehörigen. Sie fahren Pferdeschlitten und tragen Fellmäntel. Sie üben mit Pfeilbogen, um Munition zu sparen.

Über die Vor- und Nachteile dieser Verwandlung ist er sich bis heute nicht im Klaren. Kein Internet und keine Steuern, kein Papierkram, keine Übergewichtigen, saubere Luft. Was macht ein Hausarzt ohne Medikamente? Er wird zum Schamanen, denn mit dem Wald kommt die Magie. Dazu genügen die alten Malkästen seiner Kinder. Er erfindet Symbole und Bannsprüche, hängt selbstgefertigte Amulette um, setzt Schröpfgläser, kocht Beinwell, mörsert Kräuter und legt Wickel auf. Das nächste Spital fiel 
der Planung zum Opfer, damals gab es noch die Strasse. Ein Notfall ist nur, wenn das Feuer ausgeht.

Klar, dass auch das Telefon eines Tages nicht mehr funktionierte. Sie haben uns Schritt für Schritt abgehängt, ohne Abstimmung, nicht einmal angekündigt, denkt er beim Reinigen der Instrumente. Das Gezerre hätte wohl nie aufgehört. Einmal hat er von einem Kongress geträumt. Lange wurde heftig über ein Experiment diskutiert und schliesslich die grosse Planung beschlossen. Sie erklärte alle abgelegenen Gebirgstäler zu Brachzonen. Noch besucht er $\mathrm{ab}$ und $\mathrm{zu}$ einen Stammtisch bei Kerzenlicht und
Selbstgebranntem. Die Meinungen sind längst gemacht. Der Ort verschwindet im alpinen Reservat, das die urbanen Zentren einrichten. Den Jüngsten ist das egal, sie kennen nichts anderes, und die Alten haben sich damit abgefunden. Der unsichere Fussweg nach drüben ist ihnen zu beschwerlich. Ausserdem weiss keiner mehr, wie es dort aussieht. Von ferne heult ein Wolfsrudel in die Mondnacht. Die Flamme verrusst den Lampenschirm. Er wickelt den Mantel enger um sich und schraubt den Leinendocht etwas höher. Noch ist eine Seite übrig, für seine Flaschenpost. Dann ist Schluss. 